\title{
Effect of Surfactants on the Electrodeposition of Ni-SiC Composites
}

\author{
P. Narasimman, ${ }^{a, *}$ Malathy Pushpavanam $^{a}$ and V.M. Periasamy ${ }^{b}$ \\ ${ }^{a}$ Alagappa Chettiar College of Engineering \& Technology, Karaikudi-630 004, India \\ ${ }^{b}$ Abdul Rahman University, Chennai-630 048, India
}

Received 6 February 2012; accepted 28 February 2012

\begin{abstract}
The effect of various surfactants on the volume\% codeposition of $\mathrm{SiC}$ in a nickel matrix was evaluated. Of the various surfactants tried, tetra methyl ammonium hydroxide (TMAH) was found to be the best for improving the quality of the deposits as well as the homogenous distribution of particles and with reasonable volume $\%$ of silicon carbide incorporation in the matrix. Composites were produced using $1 \mu \mathrm{m}$ and 50 nanometer size powders. The effect of silicon carbide concentration and bath operating variables on the volume\% of $\mathrm{SiC}$ incorporation in the deposit and the deposition rates were estimated. Substantial improvement in mechanical properties such as hardness and wear resistance was obtained with the nano $\mathrm{SiC}$ composite compared to the micro $\mathrm{SiC}$ composite.
\end{abstract}

Keywords: $\beta$-SiC micro/nanocomposites; sediment electro-codeposition; surfactants; surface morphology; hardness and wear resistance.

\section{Introduction}

Composite electroplating is a method of codepositing insoluble particles of metallic or non-metallic compounds such as oxides, carbides, borides, nitrides, diamond, graphite, PTFE or talk in the plated layer to improve material properties such as wear resistance, lubrication, or corrosion resistance [1-4]. Due to their high wear resistance and low cost of ceramic powders, composite materials such as $\mathrm{Ni}-\mathrm{SiC}$ manufactured by electro-codeposition method have been investigated to a greater extent and successfully commercialized in the automotive and aerospace industry, particularly for the protection of friction parts $[5,6]$.

\footnotetext{
* Corresponding author. E-mail address: malathypush@yahoo.com
} 
This process can be carried out using either Conventional Electro-Co-Deposition technique (CECD), in which the electrodes are positioned vertically in the plating cell, or by Sediment Electro-Co-Deposition (SECD), in which the electrodes are positioned horizontally one over the other with sufficient inter-electrode distance, so that the particles settle on the electrode surface as sediment on the cathode as the metal deposition progresses [7, 8]. The latter has the advantage of yielding considerably higher volume\% incorporation of particles in the deposit compared to the CECD technique for a given volume\% of particles in the solution. This has the advantage of conserving the costly insoluble powders, especially those with a very fine size. Schematic representations of the CECD and SECD techniques are shown in Fig.1.
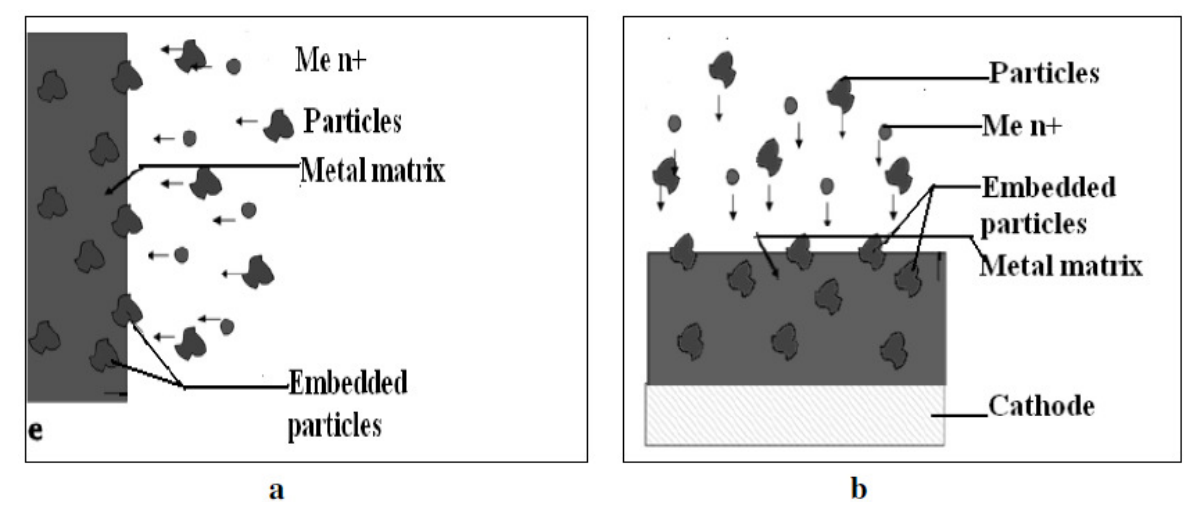

Figure 1. Schematic representation of the codeposition techniques. a) CECD; b) SECD.

Recently, the availability of ever decreasing particle sizes has expanded metal matrix composite coating's applications [9-11]. Submicron size particles dispersed into a metal matrix not only promote homogeneity of composites, due to the increased metal-particle contact surface area, but also would be a necessity for use as composite materials in micro-devices. Since components of these devices are of micro scale, the second phase material in the matrix needs to be an order of magnitude smaller, thus, up to nanometric requirement [11].

A variety of nanosized particles ranging from $4 \mathrm{~nm}$ to $800 \mathrm{~nm}$ diameters, have been successfully incorporated into metallic electrodeposits [3,12-17]. By incorporating nanosized particles, properties of the coating such as hardness, wear resistance, strength, scratch resistance, high-temperature corrosion protection, oxidation resistance and self-lubrication, etc., are significantly improved [18,19].

However, the reduction of particle size will decrease the codeposition content of the particles [13,18-19]. According to the literature, it was found that the smaller the particle size, the more difficult the particles embedded in the deposition layer $[13,18,20]$. Further, the codeposition of $\beta$-SiC is more difficult than that of $\alpha-\mathrm{SiC}$ [21].

Studies have also been reported on the influence of operating parameters on the codeposition of nano-SiC in the nickel matrix [17,22,23]. Gyftou et al. [24] have reported the co-deposition mechanism of micro and nano-SiC particles incorporated in nickel matrix. The electro-codeposition process, and hence the 
structure, the morphology and the properties of the composite coatings is affected by the electrodeposition parameters [25-29].

Various additives have been studied to reduce the agglomeration of particles [30], increasing the volume fraction of $\mathrm{SiC}$ particles in the deposit, good dispersion and high hardness. In general, cationic and anionic surfactants are being used to change the surface characteristics of the particles [12,30-41]. Saccharine has been used by Zimmerman et al. and Lei Shi et al. [22,42].

The properties of Ni-SiC composite coatings have been improved by producing them as gradient coatings $[23,26,43]$ and by using pulse technique or triangular waveform [23,24,35,44,45]. Nano composites have also been produced by electroless technique [37, 46-50].

The available data are varied due to the difference in the nature of the bath, type of $\mathrm{SiC}(\alpha$ or $\beta$ ) and its size, additives, current mode, or testing/ analyzing methods adopted, etc. Also, none of the above data are available on $\mathrm{Ni}-\mathrm{SiC}$ nanocomposites produced by SECD technique, in which the conditions are different from those used in CECD technique.

The aim of this work is to optimize operating conditions to produce $\mathrm{Ni}-\mathrm{SiC}$ $(\sim 50 \mathrm{~nm})$ nanocomposites from a Watt's bath containing a suitable surfactant, with maximum hardness, wear resistance, scratch resistance and roughness using SECD technique and compare the results with those of Ni-SiC microcomposite $(\sim 1 \mu \mathrm{m})$ prepared using the same technique. The effect of various surfactants on the volume $\%$ incorporation of $\beta-\mathrm{SiC}$ has been evaluated. Tetramethyl ammonium hydroxide (TMAH) is found to be the best surfactant. The composites produced were tested for their microstructural and mechanical properties and compared.

Table 1. Bath composition and conditions used for deposition.

\begin{tabular}{llc}
\hline \multicolumn{1}{c}{ Constituent } & Concentration, g/L \\
\hline $\mathrm{NiSO}_{4} 6 \mathrm{H}_{2} \mathrm{O}$ & 250 \\
$\mathrm{NiCl}_{2} \cdot 6 \mathrm{H}_{2} \mathrm{O}$ & 30 \\
$\mathrm{H}_{3} \mathrm{BO}_{3}$ & 40 \\
$\mathrm{pH}$ & $2-5$ \\
Current density & $1-3 \mathrm{~A} / \mathrm{dm}^{2}$ & \\
Temperature & $30-60{ }^{\circ} \mathrm{C}$ & \\
Agitation speed & \multicolumn{1}{c}{ Magnetic stirring, 200-600 rpm } \\
\hline
\end{tabular}

\section{Experimental}

\section{Electrolyte preparation}

The plating solution used was a standard Watts' nickel solution. The composition of the plating solution and the plating parameters are given in Table 1. The bath was prepared using laboratory grade reagents, and purified in the conventional manner [50]. Electrolyte $\mathrm{pH}$ was adjusted to 4 electrometrically using dilute sodium hydroxide or sulphuric acid.

\section{The additives}

Additives (all except saccharin are surfactants) like Triton X-100 (TX), Dodecyl sulphate (DDS), Saccharin (SAC), Cetyl trimethyl ammonium bromide (CTAB), Tetramethyl ammonium iodide (TMAI) and Tetramethyl ammonium 
hydroxide (TMAH), were prepared as aqueous solutions and added to the bath at a fixed concentration. The volume\% incorporation of $\mathrm{SiC}$ in the deposits and the homogenous distribution of $\mathrm{SiC}$ in the deposits, produced by $\mathrm{CECD}$ technique using $50 \mathrm{~g} / \mathrm{L}$ of $1 \mu \mathrm{m}$ size $\beta-\mathrm{SiC}$ in the bath, were examined. The effect of varying the concentrations of $\mathrm{CTAB}$ and TMAH on the volume\% incorporation of $\mathrm{SiC}$ in the deposit was compared using CECD and SECD techniques.

\section{SiC particles preparation}

$\mathrm{SiC}$ particles with a mean diameter of $1 \mu \mathrm{m}$ and $50 \mathrm{~nm}$ (beta phase, ALFA AESAR \& M/S Sigma Aldrich respectively) were used. All particles were used as received without any purification treatment. The particles were blended in a mortar with a little of the electrolyte and the required volume of the surfactant initially to make it as a paste, then added to the required volume of the electrolyte, treated ultrasonically for 15 minutes, and stirred well in a magnetic stirrer for 30 minutes before deposition for homogenizing.

\section{Plating details}

$250 \mathrm{~mL}$ of the fresh electrolyte were taken for each set of experiments. The bath was heated using a thermostat. Deposition was carried out for constant coulombs so as to obtain identical deposit thicknesses (around $50 \mu \mathrm{m}$ ). Mild steel cathodes of $10 \times 2.5 \mathrm{~cm}$ were used exposing an effective plating area of $4 \times 2.5 \mathrm{~cm}$ by suitable masking procedures. The cathodes were pretreated in a cleaner solution, rinsed, acid dipped and washed well before entering into the plating solution.

For CECD technique, used to evaluate the additives, the cathodes were positioned vertically as shown in Fig. 1a, facing the anode (plating grade, INCO). The particle concentration in the electrolyte was maintained as $50 \mathrm{~g} / \mathrm{L}$. The electrolyte was stirred continuously using a mechanical stirrer at a speed of 800 rpm in order to keep the particles in suspension. For SECD, the plating area of the cathode was bent at right angles so as to face the nickel anode placed above the cathode as shown in Fig. 1b. For the additive's evaluation the concentration of $\mathrm{SiC}$ was maintained at $5 \mathrm{~g} / \mathrm{L}$. This was kept in suspension by intermittent stirring using a magnetic stirrer at the rate of 30 seconds stirring after every 10 minutes interval.

For other studies, the concentration of the particles in the bath was varied between 1-10 g/L. Keeping the concentration of the particles constant $(5 \mathrm{~g} / \mathrm{L})$, the current density, $\mathrm{pH}$ of the electrolyte, bath temperature and stirring speed were varied from $1-3 \mathrm{~A} / \mathrm{dm}^{2}, 2-5,40-60{ }^{\circ} \mathrm{C}, 200-600 \mathrm{rpm}$, respectively.

\section{Volume\% of silicon carbide in the deposit}

The volume \% of SiC co-deposited in the nickel matrix were measured using a Scanning Electron Microscope (SEM, HITACHI- Model S - 3100 N, Japan) fitted with an Energy dispersive X-Ray (EDX) system. The above EDX analysis was done on the surface as well as cross section of the specimen. The coated specimen was mounted on an araldite baking, sectioned, metallographically polished and etched in Nital solution before cross sectional imaging and analysis. 


\section{Microstructure examination}

Micro structural examination of the composites was made using SEM at different magnifications. Cross-sectional analysis of the composites was made by mounting the specimens in araldite baking, sectioning, metallographic polishing, etching and then examining with SEM.

A high resolution Transmission Electron Microscope (JEOL, JEM 2100 TEM, USA) was used to visualize the presence of Nano-SiC in nickel matrix since it was very difficult with SEM. The nano composite coating was peeled off from the deposited substrate and a foil of $3 \mathrm{~mm}$ diameter was obtained using a disc punch, and it was further thinned by using a Gatan Precision Ion Polishing System.

\section{Micro hardness}

Micro hardness of the deposits produced by varying volume\% of $\mathrm{SiC}$ and the operating conditions was estimated using a Vickers micro-hardness tester, (METATECH, Model MVH- I -Pune, India) applying a load of $50 \mathrm{gms}$.

\section{Wear loss estimation}

Weight loss method

The composites were tested for wear loss using a reciprocating type wear tester provided with a $6.3 \mathrm{~mm}$ steel ball and a piezo-electric sensor to measure the force (Wear Tester, DUCOM, 181-106-M, DUCOM Instruments Pvt. Ltd, Bangalore, India). The test specimen size was $50 \mathrm{~mm}$ x $25 \mathrm{~mm}$. The entire operations of the wear tester have been carried out using a WINDUCOM operating software.

A stainless steel spherical ball of $6.3 \mathrm{~mm}$ diameter was allowed to reciprocate for $10 \mathrm{~mm}$ stroke length over the coated specimen with a normal load of $1 \mathrm{~N}$ for 360 reciprocating cycles. Each specimen was tested for wear loss for 360 cycles, i.e., 5 runs consisting of 72 reciprocating cycles for each run of $10 \mathrm{~mm}$ stroke. 72 cycles for each run have been obtained by reciprocating the spherical ball at the rate of 2 cps for 36 seconds. The wear loss for each test specimen was measured after every five test (average of duplicate experiments) runs, i.e., after 360 reciprocating cycles using an electronic digital weighing balance with an accuracy of $0.01 \mathrm{mg}$.

\section{Results and discussion \\ Effect of surfactant}

Fig. 2 and 3 show the effect of various surfactants/additives on the volume\% of $\mathrm{SiC}$ in the nickel deposit, using CECD technique. Triton $\mathrm{X}-100$, a non-ionic surfactant, dodecyl sulphate, an anionic surfactant, and saccharin, have very little effect on improving the volume\% of $\mathrm{SiC}$ incorporation in the nickel matrix. However, the cationic surfactants, especially CTAB, TMAI and TMAH, have a tremendous influence on the $\mathrm{SiC}$ incorporation percentage. They increased the volume $\%$ of $\mathrm{SiC}$ incorporation at $2 \mathrm{~A} / \mathrm{dm}^{2}$ from $3 \%$ to $7-8 \%$. Since it was feared that iodide ion may affect the deposit qualities and bath function, CTAB and TMAH were taken for further studies. 


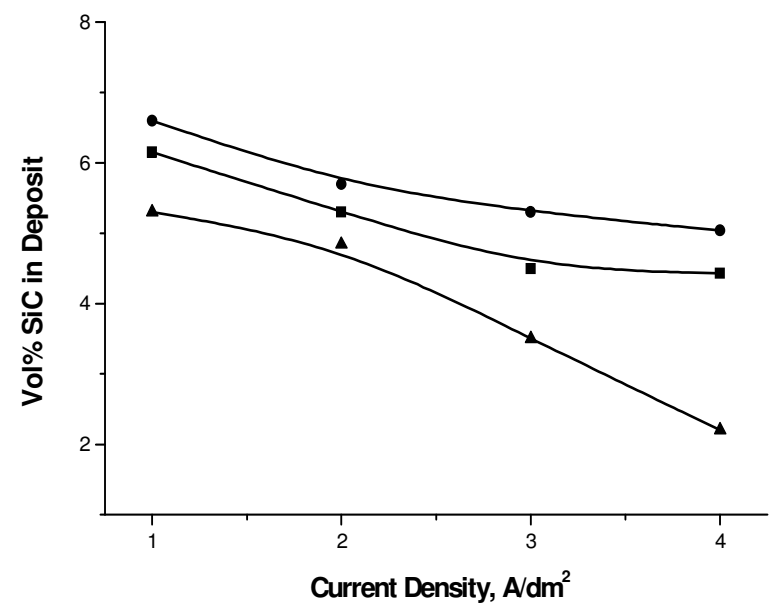

Figure 2. Effect of additives on the volume\% incorporation of micro-SiC in the deposit at different current densities. Additives $(0.001 \mathrm{M})$ : -----TX; --•--SLS; -- $\mathbf{\Delta}$--SAC. SiC conc. in the bath $50 \mathrm{~g} / \mathrm{L}$; CECD technique, $\mathrm{pH} 4$; Temperature $60{ }^{\circ} \mathrm{C} ; 800 \mathrm{rpm}$.

The colloidal particles in aqueous solution are in charged state. Consequently, a charged particle suspended in an electrolyte solution tends to be surrounded by an ionic cloud. It was reported that the surface charge of the $\mathrm{SiC}$ can adsorb $\mathrm{Ni}^{2+}$ ions and change the polarity of the $\mathrm{SiC}$ from negative to positive in an aqueous solution containing $\mathrm{Ni}^{2+}$ ions [21]. Similarly, the addition of surfactants helps modifying the surface charge and decrease particle agglomeration, and thereby enhances their electrostatic adsorption on the cathode surface [51]. It has also been reported that the surfactants change the zeta potential of the particles. The addition of surfactants decreases the agglomeration of particles so that the amount of effective particles would be significantly increased resulting in higher amounts of the codeposited $\mathrm{SiC}$ in the nickel matrix.

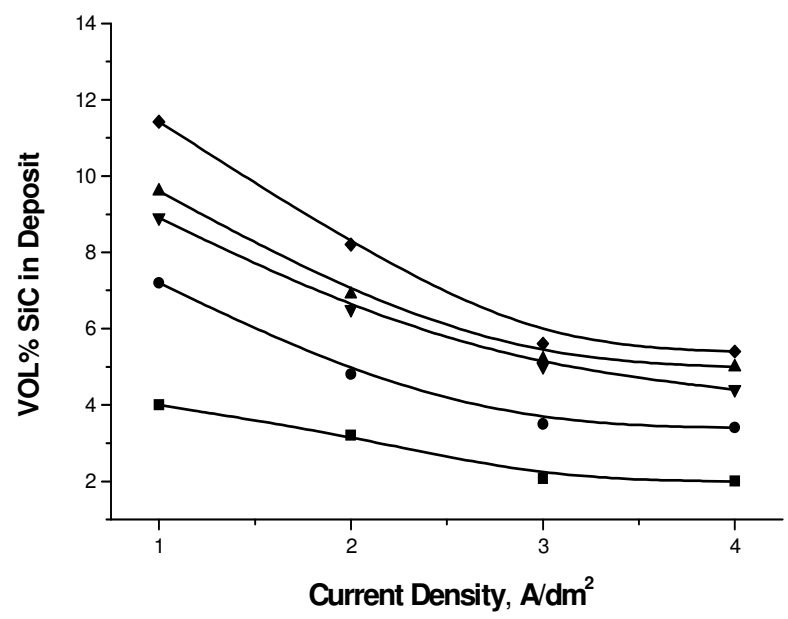

Figure 3. Effect of additives on the volume\% incorporation of micro-SiC in the deposit at different current densities. Additives $(0.001 \mathrm{M})$ : --⿴--Nil; --•--DDA; -- $\boldsymbol{\Delta}$--CTAB;-$\boldsymbol{\nabla}$--TMAI; -- --TMAH. Conditions as above. 


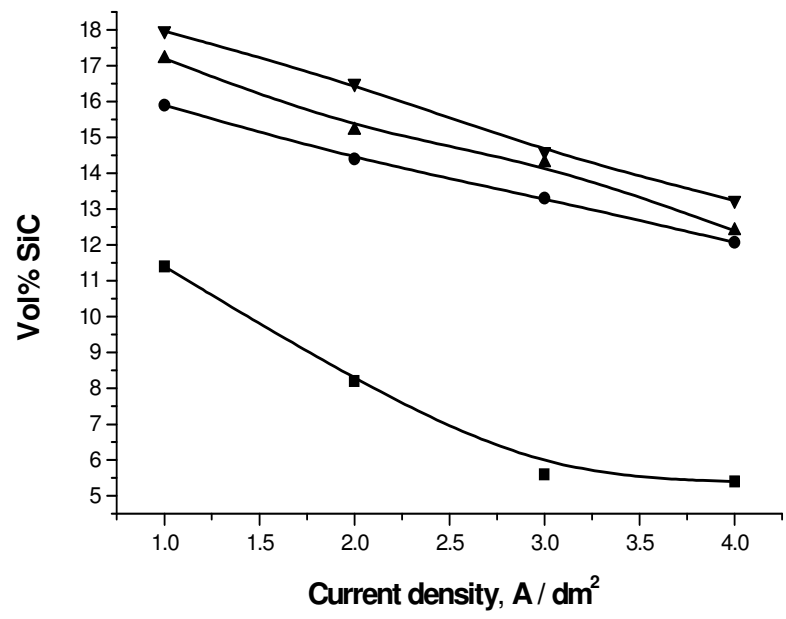

Figure 4. Effect of TMAH concentration on the volume\% of micro SiC incorporation in

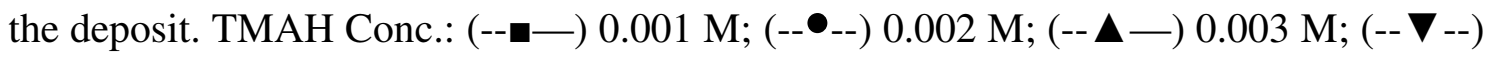
$0.004 \mathrm{M}$. Conditions as above.

Fig. 4 and 5 show the effect of increasing the concentration of CTAB and TMAH on the volume\% incorporation of $\mathrm{SiC}$ in the nickel matrix under CECD technique. Increase in their concentration helps increasing the volume $\% \mathrm{SiC}$ incorporation in both cases. However, CTAB causes excessive foaming in the bath with increasing concentration, which makes not only the co-deposition difficult but also makes the deposit non-uniform. Maximum volume\% of $\mathrm{SiC}$ could be obtained with TMAH than CTAB. In the case of TMAH, though foaming problem was not encountered, the deposit became dark and powdery at higher concentrations. This is attributable to more surfactant molecules being available for adsorption onto the particles surface, increasing the strength of the surface charge on the particles leading to stronger attraction to the cathode surface [26].

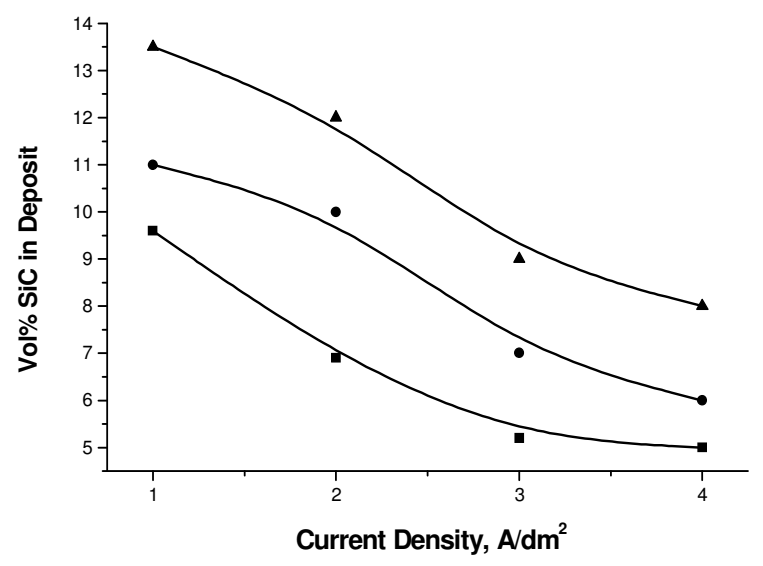

Figure 5. Effect of CTAB concentration on the volume\% of micro SiC incorporation in the deposit. CTAB Conc.: (--ח-) $0.001 \mathrm{M}$; (--•-) $0.002 \mathrm{M}$; (-- $\mathbf{\Delta - )} 0.004$ M. Conditions as above. 


\section{Effect of surfactant on deposition technique}

Fig. 6 shows the effect of increasing the concentration of CTAB and TMAH on the volume\% incorporation of $\mathrm{SiC}$ in the nickel matrix under SECD technique. At a concentration of $0.002 \mathrm{M} / \mathrm{L}$ TMAH, with $5 \mathrm{~g} / \mathrm{L} \mathrm{SiC}$ in solution at $2 \mathrm{~A} / \mathrm{dm}^{2}$, $\mathrm{pH} 4,60{ }^{\circ} \mathrm{C}$ and with $400 \mathrm{rpm}$ stirring the volume\% increased to $29.8 \%$ and $25.5 \%$ for

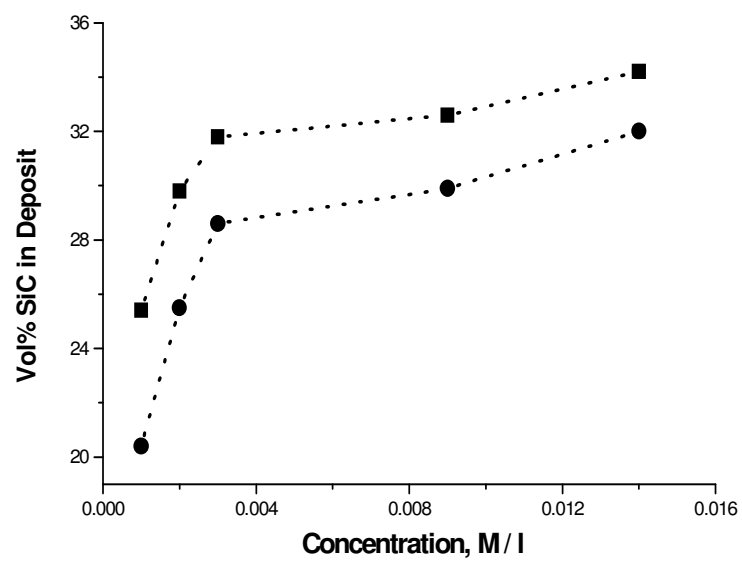

Figure 6. Effect of $\mathrm{CTAB}$ and $\mathrm{TMAH}$ concentration on the volume\% of micro $\mathrm{SiC}$ incorporation in the deposit. ---- TMAH; --•-- CTAB. SiC conc. in the bath $5 \mathrm{~g} / \mathrm{L}$; SECD technique, $\mathrm{pH} 4$; Temperature $60^{\circ} \mathrm{C} ; 400 \mathrm{rpm}$.

TMAH and CTAB, respectively, and problems such as loss of deposit quality/ foaming faced at higher concentration of the additives were more under SECD technique, due to the higher amount of particle incorporation. Considering the higher volume\% and other microstructural properties discussed below, TMAH was selected for further experiments. The advantage of using SECD technique can be very well appreciated by the nearly 4 times increase in the volume\% incorporation with ten times lower $\mathrm{SiC}$ concentration in the bath $(5 \mathrm{~g} / \mathrm{L}$ as against $50 \mathrm{~g} / \mathrm{L})$.
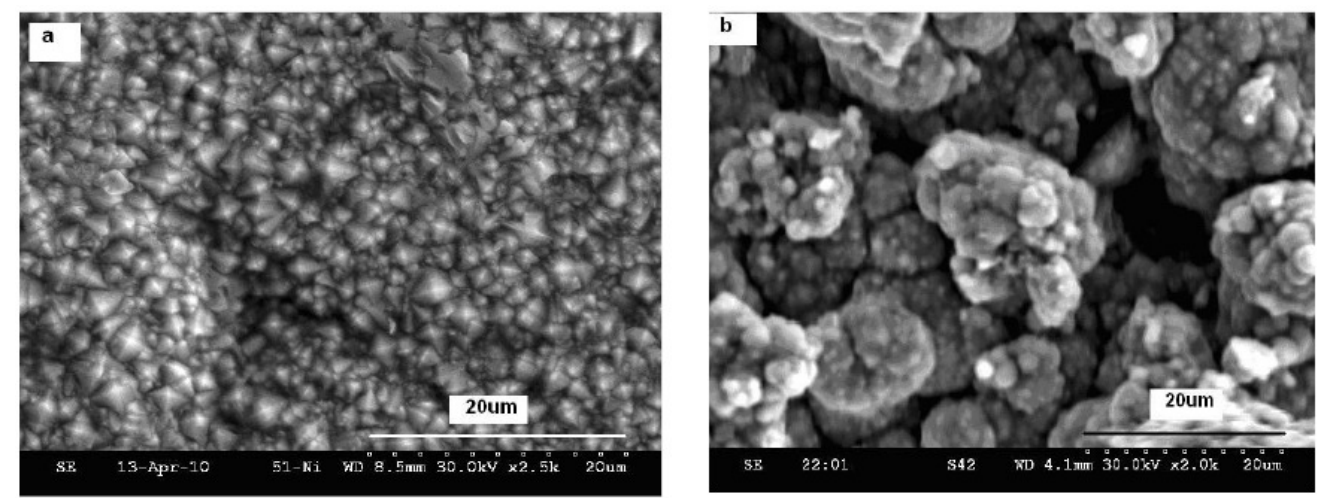

Figure 7. SEM micrographs of the deposits: a) pure nickel; b) Ni-micro SiC composite without surfactant. 


\section{Surfactant effect on microstructure}

As shown in Fig. 7a and b, the micrograph of the electrodeposited nickel consists of pyramidal crystals with pronounced crystallographic polyhedral form with equigrannular structure $[15,52]$, whereas the composite coating without any surfactant shows a spherical nodular surface structure. The particle distribution is not clear. Figs. 8a-c show the SEM micrographs of Ni-1 $\mu \mathrm{m} \mathrm{SiC} \mathrm{composites} \mathrm{at}$ various concentrations of CTAB. At very low concentration $(0.003 \mathrm{M})$, though the deposit clearly shows the distribution of particles, it still has a nodular structure. At $0.007 \mathrm{M}$, the nodular structure has been further modified. With still higher concentrations, $(>0.01 \mathrm{M})$, the particle incorporation is much higher than the matrix metal and the presence of voids in between the grains is observed.

Figs. 9a-c show the effect of TMAH addition on the SEM microstructure of the composites. Addition of $0.002 \mathrm{M}$ TMAH refines the structure considerably which is evident from the less agglomerated $\mathrm{SiC}$ particles and a smooth structure. The change in the morphology has been attributed to the change in the preferred orientation [15]. At $0.02 \mathrm{M}$, the extent of particle incorporation is considerably increased uniformly, probably due to the increased surface charge, and above $0.05 \mathrm{M}$, as observed for CTAB, the structure consists of isolated grains with voids in between. In general, the deposit morphology obtained with TMAH was much finer than that with CTAB.

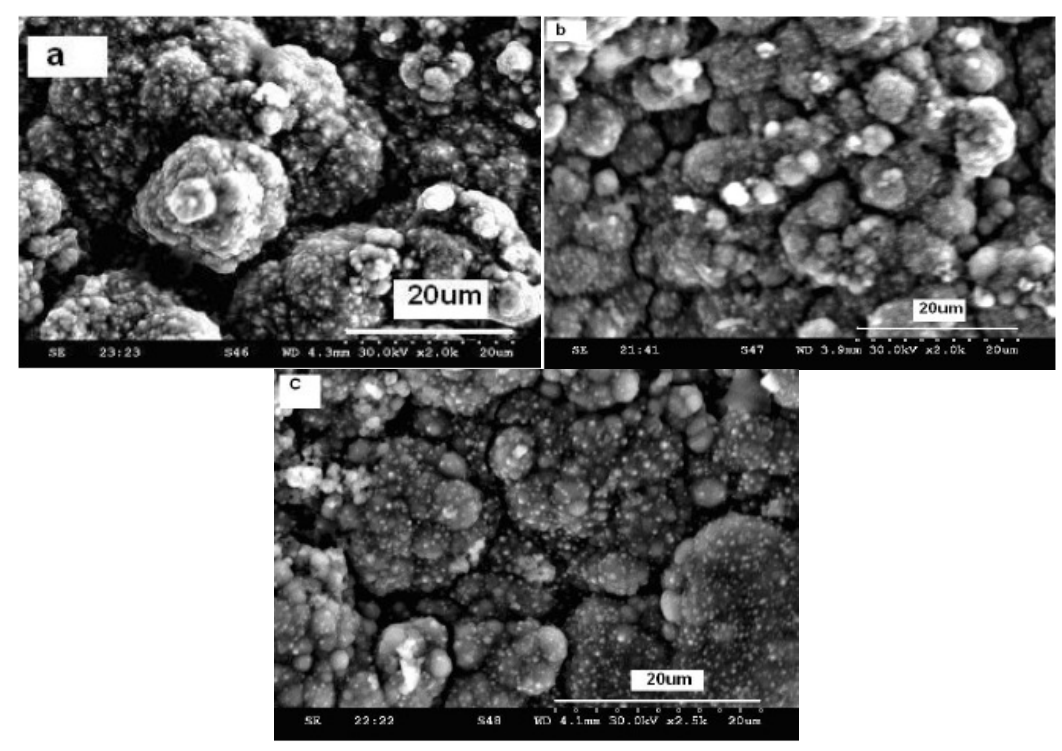

Figure 8. SEM micrographs of the Ni-micro $\mathrm{SiC}$ composite with $\mathrm{CTAB}$ as the surfactant. CTAB: a) $0.003 \mathrm{M}$; b) $0.007 \mathrm{M}$; c) $0.01 \mathrm{M}$. SiC conc. in the bath $5 \mathrm{~g} / \mathrm{L}$; SECD technique, $\mathrm{pH} 4$; Temperature $60{ }^{\circ} \mathrm{C} ; 2 \mathrm{~A} / \mathrm{dm}^{2} ; 400 \mathrm{rpm}$.

\section{Effect of particle size on the codeposition}

The codeposition of $\mathrm{SiC}$ particles smaller than $100 \mathrm{~nm}$ is more difficult than micron and submicron size particles [7, 24, 30, 53]. Nanoparticles have a strong tendency to agglomerate due to their high activity [16]. They agglomerate in the plating bath as well as in the deposit even at low concentrations. The agglomeration by forming large particles reduces the number of effective particles. Moreover, a larger agglomerated particle enhances roughness of the deposit and causes its spalling from the matrix since the bonding is insufficient. 
Fig. 10a and b show the SEM microstructure of micron sized SiC composite and the TEM image of the nano sized $\mathrm{SiC}$ composite. Both are homogenously distributed in the matrix.

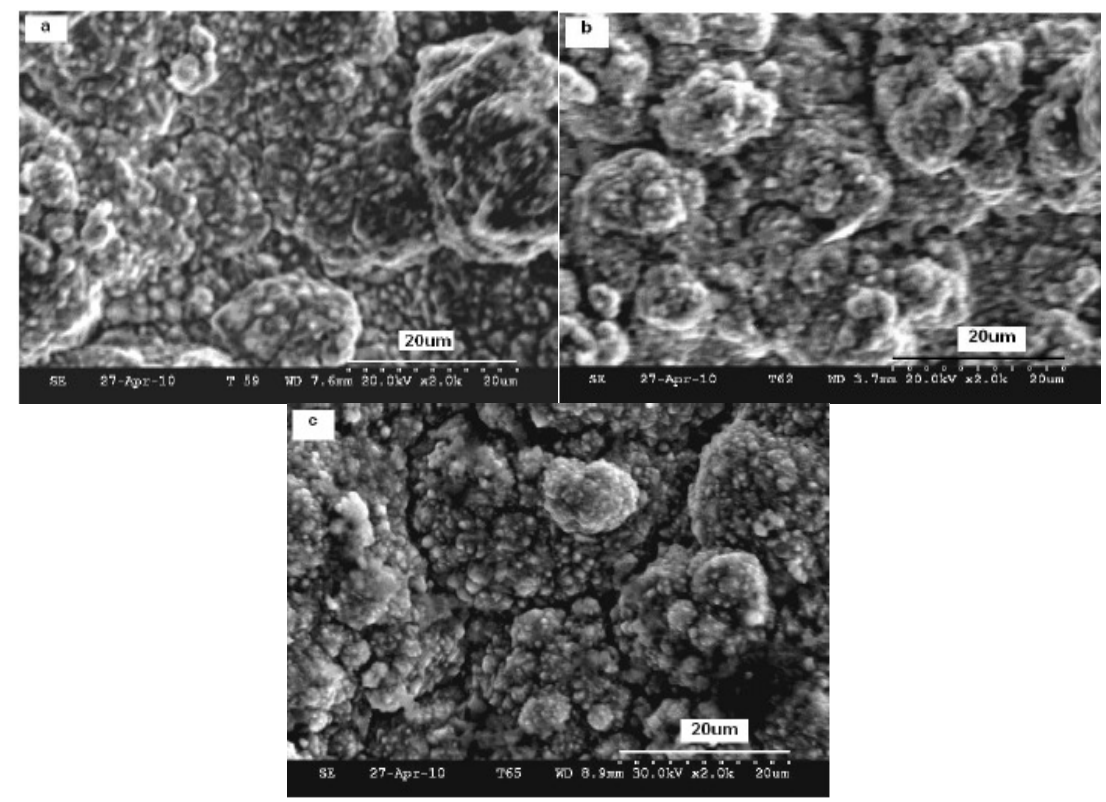

Figure 9. SEM micrographs of the Ni-micro $\mathrm{SiC}$ composite with TMAH as the surfactant. TMAH: a) $0.002 \mathrm{M}$; b) $0.02 \mathrm{M}$; c) $0.05 \mathrm{M}$. SiC conc. in the bath $5 \mathrm{~g} / \mathrm{L}$; SECD technique, $\mathrm{pH} 4$; Temperature $60{ }^{\circ} \mathrm{C} ; 2 \mathrm{~A} / \mathrm{dm}^{2} ; 400 \mathrm{rpm}$.

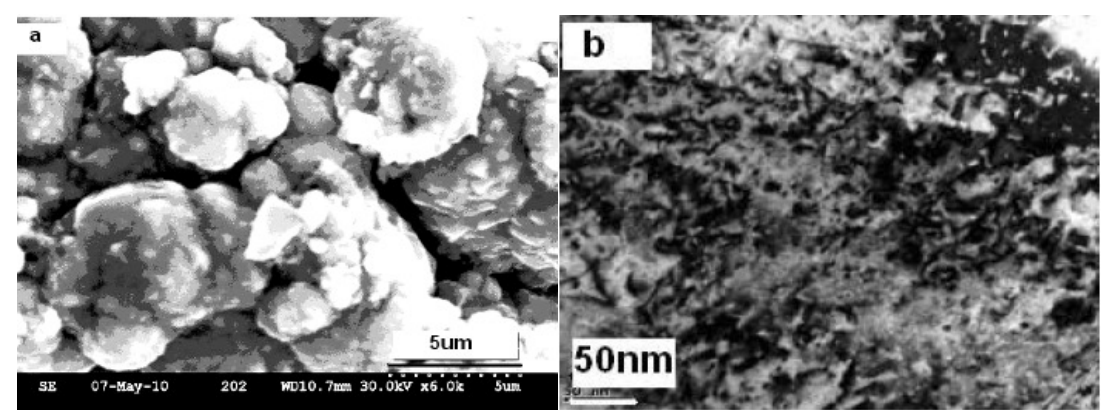

Figure10. Micrographs of the composites. a) SEM micrograph of micro composite; b) TEM picture of Ni-nano SiC composite.

It has been reported that codeposition of $\beta$-SiC is more difficult than $\alpha-\mathrm{SiC}$ due to the difference in their zeta potential. $\alpha$-SiC particles are more negative than $\beta$ $\mathrm{SiC}$ and hence the amount of adsorbed surfactant ions is smaller for the $\beta$-SiC than the former. Table 2 shows the volume $\%$ of $\beta$-SiC obtained at different conditions. The volume\% obtained for nano particles are always less than that of its counterpart. According to Garcia et al., with decreasing the particle size, the number of particles increases as well as the number density of the particles in the composite.

\section{Effect of SiC concentration in the bath}

Table 2 shows the effect of nano and micro SiC concentration on the volume\% incorporation in the deposit and their deposition rate in presence of TMAH. 
The volume\% of $\mathrm{SiC}$ in the composites, irrespective of the particle size, increased with increasing the concentration of the particles in the plating solution up to around $7 \mathrm{~g} / \mathrm{L}$ and then showed a plateau. The rising trend might be due to the increase in the number of SiC particles approaching the cathode with the increasing $\mathrm{SiC}$ content in the plating bath. Only those particles that remain adsorbed on the cathode surface for a sufficient period of time are successfully incorporated into the growing nickel matrix. Since the number of particles approaching the cathode surface increases with the increasing SiC content in the bath, they agglomerate and block the surface available for nickel deposition [14]. This results in increased actual current density for nickel deposition and also reduces the metal binder required to hold the particles making the deposit powdery.

Table 2. Effect of operating variables on the vol\% SiC incorporation in the deposit and the deposition rate.

\begin{tabular}{|c|c|c|c|c|c|}
\hline Condition & & $\begin{array}{l}\text { Vol\% micro- } \\
\text { SiC in deposit }\end{array}$ & $\begin{array}{c}\text { Deposition rate, } \\
\mu \mathrm{m} / \mathrm{hr}\end{array}$ & $\begin{array}{c}\text { Vol\% nano-SiC } \\
\text { in deposit }\end{array}$ & $\begin{array}{c}\text { Deposition rate, } \\
\mu \mathrm{m} / \mathrm{hr}\end{array}$ \\
\hline \multirow[t]{5}{*}{ SiC conc. $\mathrm{g} / \mathrm{L}$} & 1 & 24.33 & 28.86 & 18.4 & 27.75 \\
\hline & 3 & 26.00 & 29.54 & 21.53 & 27.06 \\
\hline & 5 & 29.80 & 30.47 & 23.84 & 28.64 \\
\hline & 7 & 31.16 & 30.75 & 25.51 & 29.27 \\
\hline & 10 & 31.64 & 30.78 & 26.38 & 29.33 \\
\hline \multirow[t]{4}{*}{$\mathrm{pH}$} & 2 & 21.80 & 25.47 & 15.36 & 24.78 \\
\hline & 3 & 23.10 & 28.86 & 17.88 & 26.98 \\
\hline & 4 & 29.80 & 30.47 & 23.84 & 28.64 \\
\hline & 5 & 26.50 & 28.79 & 21.45 & 28.18 \\
\hline \multirow[t]{3}{*}{ C.D, $\mathrm{A} / \mathrm{dm}^{2}$} & 1 & 31.40 & 15.57 & 28.70 & 14.66 \\
\hline & 2 & 29.80 & 30.47 & 23.84 & 28.64 \\
\hline & 3 & 17.10 & 41.69 & 15.40 & 39.44 \\
\hline \multirow[t]{3}{*}{ Temperature, ${ }^{\circ} \mathrm{C}$} & 40 & 31.65 & 30.32 & 26.10 & 28.61 \\
\hline & 50 & 30.64 & 30.42 & 24.07 & 28.61 \\
\hline & 60 & 29.80 & 30.47 & 23.84 & 28.64 \\
\hline \multirow[t]{2}{*}{ Stirring rate, rpm } & 200 & 26.23 & 29.58 & 20.39 & 27.71 \\
\hline & 400 & 29.80 & 30.47 & 23.84 & 28.64 \\
\hline
\end{tabular}

It is observed that the volume\% incorporation of nano $\mathrm{SiC}$ particles in the composite is lower than that of the micron sized particles at all concentrations. This could be attributed to the relatively higher extent of agglomeration of nano sized particles in presence of TMAH compared to the latter. However, due to the smaller size, their number density in the composite is higher, which is responsible for their improved mechanical properties compared to the micron sized particles. The deposition rate is slightly less for the nanocomposites. This should be due to the smaller density of $\operatorname{SiC}\left(3.2 \mathrm{~g} / \mathrm{cm}^{3}\right)$ which is taken for the deposition rate calculations.

Table 2 also shows the effect of $\mathrm{pH}$, current density, temperature and stirring rate on the volume\% incorporation of the two composites and their deposition rate in presence of $0.02 \mathrm{M}$ TMAH. The volume\% incorporation of both particles shows an increasing trend with $\mathrm{pH}$ up to 4 and with increase in stirring rate. But there is a decreasing trend with current density and bath temperature which is reflected in their deposition rate. 


\section{Effect of volume\% of SiC on the properties of composites}

Table 3 shows the variation of hardness and wear resistance of the two composites with the volume $\% \mathrm{SiC}$ in the deposit. Nano composites show higher hardness and wear resistance than the micro composites. This can be attributed to the uniformly dispersed smaller sized particles with a higher number density in the matrix. The nano composites showed a maximum hardness of $385 \mathrm{VHN}$ and minimum wear loss of $0.8 \mathrm{mg}$ at around 24.0 volume $\%$, whereas the micro composites exhibited a maximum hardness of $348 \mathrm{VHN}$ and minimum wear loss of $1.8 \mathrm{mg}$ at around 29.0 volume $\% \mathrm{SiC}$ in the deposits.

Table 3. Variation of hardness and wear loss with the volume\% incorporation of $\mathrm{SiC}$ in the nano and micro composites.

\begin{tabular}{|l|c|c|c|c|c|c|}
\hline No. & \multicolumn{3}{|c|}{ Nano SiC composite } & \multicolumn{3}{c|}{ Micro SiC composite } \\
\hline & $\begin{array}{c}\text { SiC in deposit } \\
\text { Vol \% }\end{array}$ & $\begin{array}{c}\text { Hardness } \\
\text { VHN }\end{array}$ & $\begin{array}{c}\text { Wear loss } \\
\text { mgs }\end{array}$ & $\begin{array}{c}\text { SiC in deposit } \\
\text { Vol \% }\end{array}$ & $\begin{array}{c}\text { Hardness } \\
\text { VHN }\end{array}$ & $\begin{array}{c}\text { Wear loss } \\
\text { mgs }\end{array}$ \\
\hline 1 & 15.4 & 312.3 & 2.2 & 17.1 & 260.8 & 3.5 \\
\hline 2 & 17.9 & 335.1 & 1.6 & 21.8 & 287.3 & 2.8 \\
\hline 3 & 18.4 & 338.4 & 1.4 & 23.1 & 292.4 & 2.6 \\
\hline 4 & 20.4 & 352.7 & 1.2 & 24.3 & 305.4 & 2.4 \\
\hline 5 & 21.5 & 366.4 & 1.0 & 26.0 & 320.0 & 2.1 \\
\hline 6 & 23.8 & 384.4 & 0.8 & 26.5 & 325.5 & 2.0 \\
\hline 7 & 24.1 & 385.2 & 0.8 & 28.4 & 339.5 & 1.8 \\
\hline 8 & 25.5 & 378.5 & 1.0 & 30.5 & 348.7 & 2.0 \\
\hline 9 & 26.1 & 366.4 & 1.2 & 31.2 & 341.5 & 2.2 \\
\hline 10 & 26.4 & 362.5 & 1.2 & 31.4 & 339.2 & 2.3 \\
\hline 11 & 28.7 & 354.6 & 1.5 & 31.7 & 337.0 & 2.5 \\
\hline
\end{tabular}

\section{Conclusion}

The cationic surfactants help increasing the volume\% incorporation of $\beta$-SiC in the nickel matrix. Of all the additives investigated, TMAH is found to be the best for producing deposits with highest volume\% $\mathrm{SiC}$ incorporation and a more homogenous distribution. The SECD technique enables higher volume\% incorporation of particles in the deposit for a given volume\% of $\mathrm{SiC}$ in the bath compared to the CECD technique. Though nano composites had lower volume\% incorporation than the micro composites, they exhibited higher hardness and wear resistance than the Ni-micro $\mathrm{SiC}$ composites. This is attributed to the higher number density of particles embedded due to the smaller size.

\section{Acknowledgement}

The authors wish to express their sincere thanks to the Principal, ACCET for permission to publish this paper. Our sincere thanks are also due to the staff of Instrumentation division, Central Electro Chemical Research Institute, Karaikudi, for EDX measurements. Dr. Malathy Pushpavanam expresses her sincere thanks to All India Council for Technical Education (AICTE) for awarding the Emeritus fellowship and funding her research at ACCET, Karaikudi. 


\section{References}

1. A. Gomes, I. Pereira, B. Fernández, R. Pereiro, Electrodeposition of Metal Matrix Nanocomposites: Improvement of the Chemical Characterization Techniques, in Advances in Nanocomposites - Synthesis, Characterization and Industrial Applications, Boreddy Reddy (Ed.), InTech. 2011. p. 503.

2. A. Hovestad, L.J.J. Janssen, Electroplating of Metal Matrix Composites by Codeposition of Suspended Particles, Modern Aspects of Electrochemistry, Number 38, B.E. Conway (Ed.) Kluwer Academic/Plenum Publishers, New York, 2005

3. C.T.J. Low, R.G.A. Wills, F.C. Walsh, Surf. Coat. Technol. 201 (2006) 371.

4. J.L. Stojak, J. Fransaer and J.B. Talbot, Review of Electrocodeposition, Advances in Electrochemical Science and Engineering, Volume 7. R.C. Alkire, and D.M. Kolb (Ed.) (2001).

5. L. Benea, P.L. Bonora, A. Borello, S. Martelli, F. Wenger, P. Ponthiaux, J. Galland, J. Electrochem. Soc. 148 (2001) C461.

6. F. Bratu, L. Benea, J.-P. Celis, Surf. Coat. Technol. 201 (2007) 6940-6946.

7. R. Balaji, M. Pushpavanam, K. Yogesh Kumar, K. Subramanian, Surf. Coat. Technol. 201 (2006) 3205.

8. M. Pushpavanam, H. Manikandan, K. Ramanathan, Surf. Coat. Technol. 202 (2007) 6372.

9. R.R. Oberle, M.R. Scanlon, R.C. Cammarata, P.C. Searson, Appl .Phys. Lett. 66 (1995) 19.

10. B. Muller, H. Ferkel, Nanostruct. Mater. 10 (1998) 1285.

11. A.B. Viderine, E.J. Podlaha, J. Appl. Electrochem. 31 (2001) 461.

12. K.H. Hou, M.D. Ger, L.M. Wang, S.T. Ke, Wear 253 (9-10) (2002) 996.

13. I. Garcia, J. Fransaer, J.-P. Celis, Surf. Coat. Technol. 148 (2001) 171.

14. M.R. Vaezi, S.K. Sadrnezhaad, L. Nikzad. Colloids Surfaces A: Physicochem. Eng Aspects 315 (2008) 176.

15. M. Srivastava, V.K. William Grips, K.S. Rajam, Appl. Surf. Sci. 253 (8) (2007) 3814.

16. C. Zanella, M. Lekka, P.L. Bonora, J. Appl. Electrochem. 39 (2009) 31.

17. L. Benea, P.L. Bonora, A. Borello, S. Martelli, F. Wenger, P. Ponthiaux, J. Galland, Solid State Ionics 151 (2002) 89.

18. G. Maurin, A. Lavanant, J. Appl. Electrochem. 25 (1995) 1113.

19. S.Y. Park, R.H. Kim, J.S. Kim, C.K. Kim, J. Korean Surf. Eng. 25 (2) (1992) 73.

20. S.C. Wang, W.C.-J. Wei, Mater. Chem. Phys. 78 (2003) 574.

21. H.-K. Lee, H.-Y. Lee, J.-M. Jeon, Surf. Coat. Technol. 201 (2007) 4711.

22. A.F. Zimmermann, G. Palumbo, K.T. Aust, U. Erb, Mater. Sci. Eng. A 328 (2002) 137.

23. P. Gyftou, E.A. Pavlatou, N. Spyrellis, Appl. Surf. Sci. 254 (2008) 5910.

24. P. Gyftou, M. Stroumbouli, E.A. Pavlatou, P. Asimidis, N. Spyrellis, Electrochim. Acta 50 (2005) 4544.

25. L. Liu, H. Zhao, W. Hu, B. Shen, Mater. Letters 59 (2005) 3014.

26. A. Sohrabi, A. Dolati, M. Ghorbani, A. Monfared, P. Stroeve, Mater. Chem. Phys. 121 (2010) 497. 
27. K.C. Chan, C.L. Wang, K.F. Zhang, G. Pang, Scripta Materialia 51(2004) 605.

28. C.S. Lin and K.C. Huang, J. Appl. Electrochem. 34 (2004) 1013.

29. S.K. Kim, H.J. Yoo, Surf. Coat. Technol. 108-109 (1998) 564.

30. Ming-Der Ger, Mat.Chem.Phys. 87 (2004) 67.

31. Y.C. Chen, M.D. Ger, W.H. Hwu, S.L. Kuo, K.H. Hou, J. Chin.Colloid Interface Soc. 24 (2002) 89.

32. K.-H. Houa, W.-H. Hwub, S.-T. Ke, M.-D. Ger, Mater. Chem. Phys. 100 (2006) 54.

33. C.F. Malfatti, H.M. Veit, T.L. Menezes, J.Z. Ferreira, J.S. Rodriguês, J.-P. Bonino, Surf. Coat. Technol. 201(2007) 6318.

34. N.K. Shrestha, M. Masuko, T. Saji, Wear 254 (2003) 555-564.

35. L. Orlovskaja, N. Periene, M. Kurtinaitiene, S. Surviliene, Surf. Coat. Technol. 111 (1999) 234.

36. A. Grosjean, M. Rezrazi, P. Berçot, Surf. Coat. Technol. 130 (2-3) (2000) 252.

37. Y. Zhou, H. Zhang, B. Qian, Appl. Surf. Sci, 253 (2007) 8335-8339.

38. M. Lekka, N. Kouloumbi, M. Gajo, P.L. Bonora, Electrochimica Acta 50 (2005) 4551.

39. N.K. Shrestha, I. Miwa, T. Saji, J. Electochem. Soc. 148 (2001) C106.

40. N. Zhao-xia, C. Fa-he, W. Wei, Zhang Zhao, Z. Jian-qig, C. Chu-nan, Trans. Nonferrous Met. Soc. China 17 (2007) 9.

41. A. Hovestad, L.J.J. Janssen, J. Appl. Electrochem. 25 (1995) 519-529.

42. L. Shi, C. Sun, P. Gao, F.g Zhou, W. Liu, Appl. Surf. Sci. 252 (2006) 3591.

43. H. Wang, S. Yao, S. Matsumura, J. Mater. Processing Technol. 145 (2004) 299.

44. A.F. Zimmerman, D.G. Clark, K.T. Aust, U. Erb, Material Letters 52 (2002) 85.

45. F. Hu, K.C. Chan, Appl. Surf. Sci. 243 (2005) 251.

46. A. Grosjean, M. Rezrazi, J. Takadoum, P. Berçot, Surf.Coat Technol. 137 (2001) 92.

47. Xue-tao Yuan, Dong-bai Sun, Hong-ying Yu, Yu Wang, International Journal of Minerals, Metallurgy and Materials 16 (2009) 444.

48. A. Grosjean, M. Rezrazi, P. Berçot, Metal Finishing 101 (3) (2003) 33.

49. G. Sheela, M. Pushpavanam, Metal Finishing 100 (2002) 45.

50. M. Schlaisnger and M. Povlov (Ed.,) Modern Electroplating, John Wiley \& Sons, Inc. NY, (2000) p. 139.

51. A. Abdul Aal, K.M. Ibrahim, Z. Abdul Hameed, Wear 260 (2006) 1070.

52. V. Medeliene, Surf. Coat. Technol. 154 (2002) 104.

53. B.S. Xu, H. Wang, S. Dong, B. Jiang, W. Tu, Electrochem. Commun. 7 (2005) 572. 